\title{
Leitura e escrita em fanfic: deslocamentos do leitor ao jogador
}

Maria de Lourdes Rossi Remenche"

Mérie Ellen Weber Oliveira*

\section{Resumo}

A contemporaneidade é marcada por transformações relacionas não só aos diferentes setores da sociedade, mas também ao modo como os sujeitos interagem na cibercultura e produzem sentidos. Nessa perspectiva, as práticas de leitura e escrita se deslocaram e ganharam novos contornos e possibilidades. Considerando esse contexto, este artigo busca analisar alguns deslocamentos do leitor possibilitados pelas novas mídias. A partir de uma metodologia qualitativo-interpretativista e ancorada nas ideias do Grupo de Nova Londres para discutir os multiletramentos, a análise do gênero fanfic revela que as dimensões propostas pelos teóricos dos multiletramentos para compreender as novas mídias - o agenciamento, a divergência, a multimodalidade e a conceitualização - estão presentes de modo ainda sutil nas fanfics.

Palavras-chave: Letramentos. Multiletramentos. Cibercultura. Fanfic.

\section{Apresentação}

O século XXI observou em seu alvorecer a mudança do paradigma técnico-econômico, de uma sociedade voltada aos insumos baratos de energia para insumos baratos de informação, propiciados pelos

\footnotetext{
* Professora Adjunta III da Universidade Tecnológica Federal do Paraná (UTFPR) com pós-doutorado em Educação pela Universidade do Minho (UM - PT). Doutora em Linguística pela Faculdade de Filosofia e Letras da Universidade de São Paulo (USP), Mestre em Estudos da Linguagem (UEL), Especialista em Língua Portuguesa (UEL) e Graduada em Letras Vernáculas e Anglo (UEL). A pesquisadora é docente do Programa de Pós-Graduação em Estudos das Linguagens/PPGEL, líder do Grupo de Pesquisa em Linguística Aplicada (GRUPLA), e desenvolve pesquisas na área de Multiletramentos, Discusos e Práticas de leitura e escrita. E-mail: mremenche@utfpr.edu.br

** Mestranda do Programa de Pós-Graduação em Estudos de Linguagens (PPGEL), da Universidade Tecnológica Federal do Paraná (UTFPR). Licenciada em Letras Português/Inglês pela UTFPR (2018) e tecnóloga em Comunicação Institucional também pela UTFPR (2012). Participou dos Grupos de Estudo de: (1) Linguística Aplicada, voltada ao Discurso; (2) Intermidialidade, ambos do Departamento Acadêmico de Linguagem e Comunicação (DALIC) da UTFPR. Estagiou no Departamento Acadêmico de Eletrônica (DAELN), na área de comunicação, contribuindo para a troca de informações entre alunos, comunidade e professores. Além disso, trabalhou no Grupo Educacional Acesso como Assistente de Comunicação das escolas: Curso e Colégio Acesso, Curso Apogeu, Espaço Evidência e Naptec. E-mail: merie@alunos.utfpr.edu.br
}

Data de submissão: abr. 2019 - Data de aceite: jul. 2019 http://dx.doi.org/10.5335/rdes.v15i2.8887 
avanços tecnológicos na microeletrônica e telecomunicações. Nesse sentido, a sociedade antes compreendida sob a lente do "pós-industrial" passou a ser conhecida sob a égide da "informação". Por essa lógica, o modo de se comunicar e se expressar também se alteraram, principalmente em virtude das novas mídias digitais, frutos dessa mudança paradigmática. Segundo Rüdiger (2011, p. 13), a comunicação nas novas mídias:

[...] com efeito, é interativa em sentido simultaneamente específico e ampliado: ampliado, por um lado, porque permite a interação humana ativa e em mão dupla com os próprios meios e equipamento que a viabilizam; específico, de outro, porque esta circunstância permite ainda a interação social ativa e em mão dupla entre os seres humanos, ao ensejar o aparecimento de redes sociotécnicas participativas que transcendem a sua pura e simples interligação social, como ocorria na esfera da velha mídia.

Nesse sentido, é possível afirmar que essas mudanças percebidas nos setores econômicos, sociais e comunicacionais, ocorreram também no modo como os sujeitos se posicionam nas novas mídias digitais. Antes da popularização da Internet, o sujeito tinha acesso à informação por meio da televisão, do jornal, do rádio etc. Hoje, as redes sociais, os portais jornalísticos, os blogues, os videogames, as salas de bate-papo, entre outros sites possibilitaram conexões com diversas partes do mundo em tempo real, o que permitiu uma interatividade entre os sujeitos muito diferente daquela possibilitada pelas mídias antigas.

Nessa perspectiva, o modo como os sujeitos se percebem nesse mundo tão plural também se alterou e, consequentemente, as práticas de leitura e escrita ganharam novos contornos e práticas. Considerando esse contexto, este artigo busca analisar alguns deslocamentos possibilitados por essas novas mídias na atuação dos sujeitos. Para tanto, este estudo apresenta em sua fundamentação teórica, conceitos do letramento, dos multiletramentos e da cibercultura.

\section{Do letramento aos multiletramentos: deslocamentos da cibercultura}

No Brasil, o termo letramento foi introduzido por meio dos estudos da Linguística Aplicada, no final dos anos 1980, por autoras como Kato, Tfouni, Soares e Kleiman. Traduzido do inglês literacy, o termo letramento apresenta diferentes nuances semânticas. Nesta pesquisa, a perspectiva adotada é a oferecida por Kleiman (1995, p. 11), de letramento como

[...] conjunto de práticas sociais, cujos modos específicos de funcionamento têm implicações importantes para as formas pelas quais os sujeitos envolvidos nessas práticas constroem relações de identidade e de poder. 
Além disso, para a autora (1995), os Estudos de Letramento se constituem em uma vertente de pesquisa que melhor articula interesse teórico e social. Em outras palavras, os estudos nessa área contribuem para a compreensão dos impactos sociais da escrita na vida dos sujeitos, seja no ambiente escolarizado ou na vida cotidiana.

Nesse sentido, a preocupação social aliada ao interesse teórico na busca de descrições e explicações sobre o fenômeno da escrita (KLEIMAN, 1995) promoveu 0 alargamento do conceito de letramento para o de multiletramentos (CAZDEN et al., 1996; KLEIMAN, 1995). Segundo Kleiman (1995), os letramentos múltiplos ou multiletramentos envolvem as características socio-históricas e culturais do letramento. Isso implica considerar na análise os diferentes grupos e contextos em que eles estão inseridos, assim como os valores culturais desses sujeitos. Nessa lógica, o Grupo de Nova Londres (New London Group) afirma que os multiletramentos são resultado da "multiplicidade de canais de comunicação e a crescente diversidade cultural e linguística no mundo" (CAZDEN et al., 1996, p. 60). Nessa perspectiva, propõe analisar os multiletramentos como reflexo de dois importantes aspectos da linguagem em uso: (1) a variabilidade de construir significados em diferentes contextos culturais, sociais ou de domínio-específico; e (2) as novas mídias de informação e comunicação (NEW LEARNING, 200-).

O primeiro aspecto evidencia que, por meio dos multiletramentos, o sujeito é capaz de identificar diferenças em padrões de significado de um contexto para outro. Essas diferenças são consequência de inúmeros fatores (gênero, cultura, experiência de vida, a título de exemplo). De certo modo, cada troca de significado é uma troca cultural. $\mathrm{O}$ segundo aspecto ressalta que as novas mídias permitiram o crescimento de textos multimodais os quais articulam os modos escritos de significar aos padrões orais, visuais, auditivos, gestuais, táteis e espaciais da língua. Nessa perspectiva, é preciso considerar que os sujeitos estão em contato não só com representações alfabéticas da língua (código alfabético), mas também com diversos outros textos que a nova mídia, em especial a digital, oferece aos sujeitos em sua vida cotidiana (NEW LEARNING, 200-).

Em função disso, a participação nas práticas sociais que envolvem a leitura e a escrita, bem como os Estudos de Letramento, deslocou-se para a cibercultura. Nesse espaço fluido, o sujeito é visto como alguém responsável por agir no mundo e por integrar uma sociedade de reflexividade, atuando como usuário, jogador, criador ou consumidor (COPE; KALANTZIS, 2008). Tal realidade midiática digital permite ao sujeito ter con- 
tato com diferentes gêneros discursivos por meio das tecnologias digitais.

Para esse espaço plural, Cope e Kalantzis (2010) apresentam quatro dimensões que representam esquematicamente características dessas novas mídias: agenciamento (agency), divergência (divergence), multimodalidade (multimodality) e, por fim, conceitualização (conceptualization).

A primeira dimensão - agenciamento - enfatiza a mudança ocorrida na sociedade, de um perfil de comando e conformidade para um de reflexão co-construída. De acordo com Cope e Kalantzis (2010), as linhas divisórias de trabalho entre criadores e consumidores de cultura e conhecimento têm se tornado turvas, em parte devido ao desenvolvimento de novas mídias. Segundo os autores (2010), o sujeito não apenas lê, ouve e assiste, como também comenta, produz, transforma e colabora para a construção de uma nova produção, ações essas que modificaram o modo de produzir significado e, por que não, o modo como o sujeito se posiciona política, social e economicamente.

Nesse sentido, o agenciamento e as novas mídias permitem a ocorrência da segunda dimensão descrita por Cope e Kalantzis (2010) - a divergência. Essa perspectiva indica a mudança de paradigma de uma era de homogeneização para uma de divergência. Nesse contexto, as diferenças não se tornam apenas mais vívidas e contundentes, como também podem se recriar, favorecendo que sujeitos e grupos sejam ainda mais diferentes. É por meio dessa dimensão que observamos no mundo digital, por exemplo, o surgimento de mecanismos de reação, nos quais o sujeito pode curtir, amar e rir de uma publicação no Facebook de modo instantâneo, ou ainda, no Twitter, a possibilidade de curtir, amar ou salvar um tweet do qual tenha gostado. Por outro viés, é a divergência que permite que os discursos antagônicos também perpassem esses ambientes, seja por meio dos emojis de odiar e chorar do Facebook, ou pela oportunidade de comentar e se posicionar de modo contrário a alguma declaração.

Desse modo, evidencia-se a terceira dimensão apresentada por Cope e Kalantzis (2010) nos meios de comunicação - a multimodalidade. Essa dimensão compreende, grosso modo, a articulação da linguagem escrita, som e imagem como produtos de um mesmo material primário. Os conceitos de produção de significado se ampliaram e estão cada vez mais entrelaçados, segundo os autores (2010), o mundo digital permitiu um deslocamento da unidade modular baseada na produção textual do caracter para o pixel. Isso não implica que o texto verbal perdeu espaço, mas que, na sociedade de co-construção, textos verbais e visuais significam de forma complementar, ou seja, juntos. No am- 
biente digital, por exemplo, o sujeito, usuário de uma mídia social, pode não apenas argumentar por meio de um texto escrito, como também pode utilizar um meme e indicar uma música para compor sua estratégia argumentativa. $\mathrm{Ou}$, como dito anteriormente, reagir por meio dos próprios mecanismos oferecidos pela mídia social.

Por consequência, a última dimensão, a conceitualização refere-se diretamente a esse usuário das novas mídias. Segundo Cope e Kalantzis (2010, p. 96, tradução nossa ${ }^{1}$ ):

Ser um usuário das novas mídias requer um tipo de pensamento que nós [Cope e Kalantzis] chamamos de "conceitualização". No mundo do consumismo passivo, você não precisava saber muito sobre o que havia dentro da máquina (mecânica, informação, sociocultural). Para ser um jogador hoje e não apenas um espectador/leitor/consumidor, você precisa se cercar de novas arquiteturas sociais e técnicas.

Para ilustrar essa nova atitude do sujeito jogador ${ }^{2}$, Cope e Kalantzis (2004, 2010) argumentam que os mecanismos de descoberta e comunicação exigem novas formas de abstração, como aspectos de identificação de arquivos, menus e diretórios, os quais podem ser feitos em casa, de modo amador, ou por meio de taxonomias formais que podem orientar o percurso de pesquisa na internet. Além disso, a conceitualização permite que sejam usados esquemas ou ontologias para estruturar informações e conteúdos por publicação semântica, como é o caso, por exemplo, das palavras-chave utilizadas para facilitar o rastreio de determinado texto na web. A conceitualização também possibilita que uma notícia de jornal seja acompanhada por foto, infográfico, vídeo explicativo e hiperlink, por exemplo, a fim de facilitar a compreensão da matéria.

Em síntese, essas quatro dimensões reafirmam a mudança paradigmática de uma era de homogeneização para uma de divergência, na qual os sujeitos não apenas consomem, mas participam ativamente na produção de conhecimento e cultura por meio do uso de textos multimodais.

Nesse cenário, as fanfics ${ }^{3}$ ganham relevo ao possibilitar ao leitor não apenas consumir (hipotexto ${ }^{4}$ ), mas também atuar como produtor de conteúdo (hipertexto), seja por meio de comentários ou de produções próprias. Essas, inclusive, podem divergir do proposto pelo hipotexto. Segundo Cope e Kalantzis (2010), a atual era da divergência propicia recriações discordantes, mas não apenas isso, pois esses hipertextos saem do domínio da linguagem escrita para alcançar outros espaços por meio da multimodalidade, como no caso dos fanclips ${ }^{5}$.

O novo produtor de conteúdo não se limita a contar uma nova história, mas traça novas curvas de significação por meio de recursos visuais, orais, auditivos, gestuais, táteis e espaciais. 
Quando o autor de uma fanfic sugere ao seu leitor uma música para ouvir ao longo da leitura ou insere uma imagem para caracterizar uma personagem, por exemplo, ele está se apropriando de recursos multimodais. Quando a fanfic ganha linhas de interatividade, o papel de usuário é deslocado para o de jogador, no qual não basta saber que existem elementos de programação na construção de um website, é preciso entender e se apropriar dessas técnicas a fim de se tornar uma personagem dessa história.

\section{Fanfic: diferentes interações no ciberespaço}

De acordo com Rüdiger (2011, p. 50), nos últimos anos,

[...] o foco da discussão sobre a nova mídia se deslocou do meio para o conteúdo, do âmbito da técnica para o âmbito da cultura que está surgindo com a Internet.

Nesse sentido, o objetivo dos estudos das novas mídias e seus respectivos gêneros não se refere apenas a compreender a tecnologia em si, mas também suas práticas de uso de modo a analisar o sentido por trás das "experiências formativas acionadas através da cibercultura" (RÜDIGER, 2011, p. 50). Nessa perspectiva, busca-se o sentido que a nova mídia, digital e cada vez mais cotidiana, enseja por meio de seus usos entre os seus sujeitos jogadores.
Nessa lógica, o destaque está em analisar como a cibercultura e os novos gêneros impactam as práticas de leitura e escrita. Se a "cibercultura" é, como definiu Lévy (1999), um conjunto de técnicas materiais e intelectuais desenvolvidas concomitante com o crescimento do ciberespaço, de que modo as práticas se alteraram no mundo digital?

Ao pensar na 'nova universalidade', proposta por Lévy (1999), é possível depreender que, no ciberespaço, por meio da interconexão das mensagens e sua vinculação permanente com as comunidades virtuais em criação (fóruns, websites, mídias sociais), sentidos variados são construídos e estendidos de modo a se renovarem constantemente. É em virtude desse aspecto que novos gêneros, como os relacionados ao ciberespaço, interferem nas práticas de leitura e escrita, pois, em um mundo virtual, os sujeitos jogadores (COPE; KALANTZIS, 2010), exploram e atualizam simultaneamente (LÉVY, 1999) esse espaço.

Para Lévy (1999, p. 75), “Quando as interações podem enriquecer ou modificar o modelo, o mundo virtual torna-se um vetor de inteligência e criação coletivas”. Essa noção de coletividade está diretamente relacionada à dimensão de agenciamento, proposta por Cope e Kalantzis (2010), visto que se observa entre os sujeitos um perfil de reflexão co-construída, por meio da qual o sujeito contribui para a construção de uma nova 
produção, como ocorre, por exemplo, ao se produzir uma fanfic.

No Brasil, as fanfics alcançaram notoriedade com o surgimento de inúmeros fóruns dedicados à série literária britânica Harry Potter. Dentro de pouco tempo inúmeros fãs tornaram-se também produtores de histórias envolvendo o universo criado pela escritora J. K. Rowling.

A partir da popularização das fanfics, outros espaços foram sendo incorporados aos fóruns e, com isso, os websites dedicados a fanfics começaram a ganhar mais força. O Fanfic Obsession (doravante FFOBS), por exemplo, on-line desde dezembro de 2009, possui página no Facebook, conta no Twitter, canal no YouTube e perfil no Instagram. Criado para ser um espaço de compartilhamento de histórias e opiniões, tanto para autores quanto leitores, a página tem entre seus principais objetivos a democratização da leitura de textos produzidos por fãs e $o$ incentivo à escrita, ao reconhecer a importância desse gênero para a produção cultural em Língua Portuguesa.

Para incentivar a escrita, a FFOBS possui diversos programas de estímulo à produção, a começar pela política de reconhecimento das melhores histórias e autores, que estimula o interesse pela escrita. Os autores selecionados ficam em destaque à direita da página, em uma coluna específica para as top 10 fanfics. Além disso, fomenta a produção por meio de seções específicas, como os especiais e os desafios, nos quais os au- tores são provocados a escrever seguindo determinada premissa, por exemplo, por meio da influência de um álbum musical -- fanfic conhecida como Ficstape.

Para facilitar a navegação pelos mais de 50 tipos de fanfics, a FFOBS possui um layout jovial e descontraído que, a todo momento, remete às inspirações das fanfics, como as bandas de K-Pop ${ }^{6}$. $\mathrm{O}$ cabeçalho da página possui um menu no qual o leitor pode acessar: a página inicial (home); as fictions publicadas; os destaques; uma seção para leitores; os informes, que disponibiliza um classificado de oferta de ideias para escrita de fanfic; informações sobre o website; o contato e, por fim, as mídias sociais nas quais a FFOBS pode ser encontrada. Nesse aspecto de navegabilidade, é possível identificar o que Cope e Kalantzis (2010) chamam de conceitualização. Ao desenvolver diferentes mecanismos de busca (website, forum, comentários, página $\mathrm{e}$ comunidade no Facebook), as páginas permitem que o acesso a determinada informação seja dinamizado. Deste modo, o usuário, ao conhecer diferentes mecanismos de navegação, pode ser direcionado mais rapidamente à fanfic que deseja.

Outro website analisado é o Spirit Fanfics e Histórias, o qual se denomina como uma plataforma para a autopublicação de livros. Para incentivar os autores, a página menciona escritores que chegaram ao mercado editorial por meio das fanfics (um exemplo é o da escritora E. L. James, autora de Cinquenta 
tons de cinza, que se inspirou na série Crepúsculo de Stephenie Meyer).

Diferentemente da FFOBS, a Spirit possui um website com caráter mais profissional e limpo, o qual não remete ao aspecto jovial da primeira página. Seu layout sequer referencia as inspirações das fanfics. No entanto, disponibiliza aos usuários um aplicativo para acesso móvel ao conteúdo do website. Para entrar, o leitor deve se cadastrar no site e criar um login para acessar os conteúdos.

O menu de acesso às seções da Spirit está localizado no pé da página (Footer), dividida em quatro colunas: a primeira referente ao website em si; a segunda sobre anúncios, contatos e regras de postagem; a terceira com as categorias das fanfics; e a última com as mídias sociais da página. A Spirit, além das mídias sociais utilizadas pela FFOBS, também possui um perfil no Google Plus.

Assim como a FFOBS, a Spirit disponibiliza informações referentes à Língua Portuguesa, inclusive nomeia essa seção como 'Aulas de Português'. As informações referentes a essas 'aulas' são disponibilizadas pela própria equipe da página, que procura destacar aspectos da norma gramatical que provocam equívocos recorrentes na escrita. Isso só é possível porque existe uma equipe de Beta Readers (ou Leitores Beta) que faz o trabalho de leitura e revisão antecipadamente.

No que se refere ao layout das páginas, a análise evidencia a diferença entre cada um dos websites. Depois de passar por uma modificação completa entre 2017 e 2018, o que impossibilitou o acesso a algumas fanfics, a FFOBS é o site com o maior número de recursos visuais. Contudo, em essência, os dois possuem regularidade na elaboração das seções: categorias, dúvidas, contato, mídias sociais, indicações, regras de postagem, equipe, Língua Portuguesa e beta-readers.

A respeito das categorias, a FFOBS possui 25 categorias (Anime, Apresentadores, Atores; Bandas; Cantores; Doramas; Esportes; Filmes; Hein?!; Heróis; Jogos; K-Pop; Livros; Originais; Outros; Realeza; Restritas; Seriados; Slash; Youtubers; sendo as especiais as de Challenges; Contos; Especiais; Ficstape e Mixtapes). Já o Spirit Fanfics e Histórias possui 13 (Animes/Mangás; Bandas/Músicos; Cartoons; Celebridades; Concursos; Filmes; Games; Livros; Mitologias/Lendas; Originais; Quadrinhos; Séries, Novelas e TV; Youtubers e Social Media Stars), além de uma lista de 52 gêneros (de Ação até Yuri).

Todas essas categorias permitem ao leitor encontrar facilmente a fanfic que mais se adequa à sua prática de leitura. Quando essa categorização não é suficiente, páginas como as criadas no Facebook possibilitam aos leitores solicitar dicas de leitura ou, ainda, a escritura de novas fanfics. Novamente, observa-se a ênfase da dimensão da conceitualização nas novas mídias, pois 
é por meio dela que o jogador/usuário pode se localizar no universo criado nos websites das fanfics.

\section{As shortfics interativas mockingjay e we remain: uma breve análise}

Considerando as diferentes dimensões elencadas por Cope e Kalantzis (2010), este artigo se propõe a analisar as shortfics interativas Mockingjay ${ }^{7} \mathrm{e}$ We remain ${ }^{8}$, ambas baseadas na trilogia Jogos Vorazes, da autora americana Suzanne Collins. A escolha deve-se ao fato de as fanfics terem sido programadas em linguagem HTML (ou betadas, no jargão do universo das fanfics) para que o leitor participe da construção da narrativa, bem como em virtude da extensão das fanfics serem menores (shortfics).

$\mathrm{Na}$ lista de fictions disponibilizadas pelo website FFOBS, ambas as shortfics podem ser encontradas na seção 'Livros', na subseção 'Jogos Vorazes'. A primeira shortfic analisada é a Mockingjay, escrita pela autora @ Tracie ${ }^{9}$, e programada pela beta-reader @Ana. De acordo com as informações fornecidas pela autora, a shortfic está classificada para maiores de 12 anos e pertence ao gênero drama. Nesse sentido, é interessante perceber o deslocamento do gênero aventura, no hipotexto, para o gênero drama, no hipertexto. Esse movimento propõe uma nova leitura por meio da fanfic - com aspectos que podem convergir ou divergir da história original -, além disso, modifica o hipotexto ao propor uma nova leitura e novas personagens para a história. Nesse sentido, a autora prevê uma restrição para a fanfic, no caso, não ter lido previamente o hipotexto: a trilogia Jogos Vorazes. Essa restrição intensifica a interatividade e a afetividade promovida pela fanfic, ao possibilitar que o jogador seja protagonista da história, e conhecer detalhes da história para se envolver de modo a interagir com o drama das personagens.

Já nas primeiras telas da fanfic Mockingjay, ocorre, por meio de programação para interação com o jogador, o cumprimento ‘Olá!', em que a autora estabelece o primeiro contato com o jogador. $\mathrm{Na}$ tela seguinte, há um reforço à restrição colocada pela autora que reforça que a história ocorre anos depois do final de Esperança (terceiro livro da trilogia), @Tracie enfatiza a importância de conhecer o hipotexto para que o jogador tenha um melhor aproveitamento da leitura.

Essa prática reforça o caráter interacional discursivo da linguagem. Nesse sentido, entende-se que a produção de sentido ocorre em um determinado contexto em que sujeito e linguagem estão irrevogavelmente atrelados. Ao se considerar as fanfics, tem-se que seus sentidos estão diretamente relacionados à leitura prévia dos hipotextos, à leitura e compreensão dos hipertextos, bem 
como à participação na fanfic por meio da interatividade produzida na dinâmica do ciberespaço.

Diante desse aspecto, a interação realizada na Tela 3 (Figura 1 ) sugere a primeira manifestação do que se entende por agenciamento (COPE; KALANTZIS,
2010). Isso ocorre, pois ao fornecer um nome para a personagem, a história não só se personaliza como também é reescrita. Desse modo, a fanfic torna-se um lugar no qual o leitor é inserido na história; seja por meio do seu próprio nome ou por meio de um nickname.

Figura 1 - Tela 3

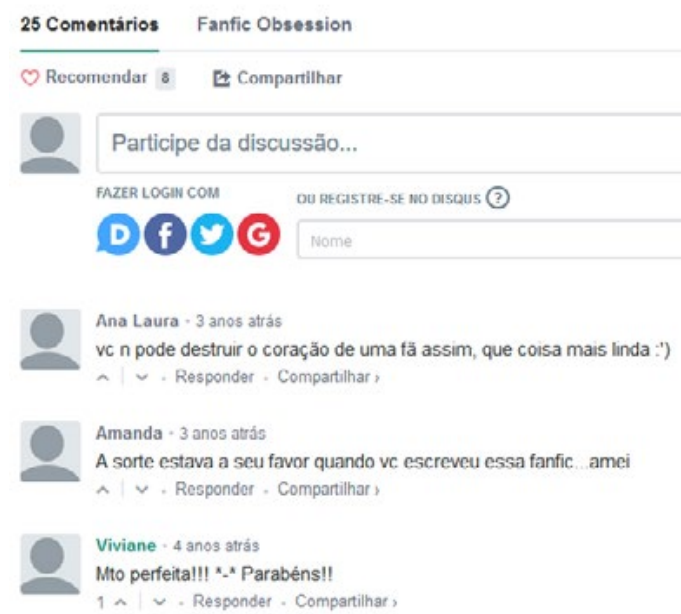

Fonte: as autoras (2018)

Nota: Se você pudesse dar um nome à filha de Katniss e Peeta, qual seria? Pode ser o seu, se quiser. (Observação: a escolha da pesquisadora foi pelo nome 'Magnólia').

Após definir o nome da personagem, a penúltima caixa de diálogo indica os votos da autora para uma boa leitura, bem como um convite para comentários $^{10}$. Essa necessidade pelo feedback do leitor corrobora a mudança percebida por Cope e Kalantzis (2010) no perfil do usuário das novas mídias. Leitores são convidados a dialogar sobre os conteúdos lidos, de modo a contribuir para novas leituras do texto, indicações para outras produções ou ainda como motivadores para a continuação das histórias.

Quando se analisa o universo das fanfics, verifica-se que esse diálogo ocorre por meio dos comentários propriamente ditos e pelas recomendações. Em Mockingjay, por exemplo, a autora recebeu 25 comentários (Figura 2) e 8 recomendações de leitura por meio do ícone 'Recomendar'. Essas reações à publicação corroboram a ideia de 'diver- 
gência' proposta por Cope e Kalantzis (2010), por meio da qual o sujeito pode se posicionar em relação àquele texto. Isso só é possível por que o usuário das novas mídias, o jogador, conhece a arquitetura social e técnica por trás desse universo. Sendo assim, pode comentar, recomendar, reagir a uma publicação.

Figura 2 - Interação dos leitores

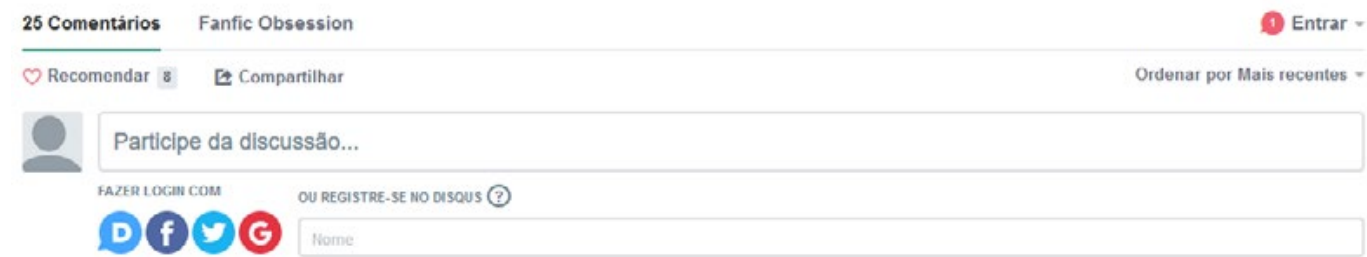

Ana Laura - 3 anos atrás

ve $n$ pode destruir o coração de uma fă assim, que coisa mais linda :")

$\wedge \mid \checkmark$. Responder - Compartilhar,

Amanda $\cdot 3$ anos atrás

A sorte estava a seu favor quando vc escreveu essa fanfic. amei

$\wedge \vee$. Responder - Compartilhar ?

Viviane -4 anos atrás

Mto perfeita!!! *_* Parabéns!!

$1 \cap \checkmark$. Responder - Compartilhar,

Fonte: as autoras (2018).

Além disso, o fato de a autora @Laís poder produzir uma continuação para a história de Jogos Vorazes por meio da fanfic dialoga com o que Cope e Kalantzis (2010) definem como 'divergência'. Apesar de não demonstrar um posicionamento antagônico, a autora @Tracie, bem como seus leitores reforçam a ideia de que é possível recriar, recontar ou adicionar informações a um hipotexto.

Desse modo, destaca-se a possibilidade de dar novos contornos, traçar novas linhas para uma história já conhecida, tendo em vista aspectos como as diferentes experiências dos autores das fanfics, assim como de seus leitores, os quais são influenciados por essa experiência. De certo modo, as fanfics interativas tornam-se um espaço também para representatividade, seja por meio do nome utilizado para integrar a história ou por intermédio das frases diretamente relacionadas ao leitor.

Essa interação autor - leitor não influencia apenas na produção de sentidos, como supracitado, mas também a polifonia. Esse conceito é desenvolvido por Bakhtin (2010), em Problemas da Poética de Dostoiévski, que argumenta que o romance tem como característica a plurivocalidade, ou seja, possui diversas vozes, as quais se mantêm equipolentes, 
sem subordinação à consciência do autor. Além disso, em muitos casos, essas vozes não são explicitadas ao leitor, que para identificá-las, muitas vezes, precisa ter lido diversos hipotextos.

Ao aplicar o conceito de polifonia às fanfics, é possível inferir que algumas dessas vozes são direcionadas ao futuro leitor por meio da descrição da fanfic ou pela seção na qual se encontra. Desse modo, o leitor que desconhece o hipotexto pode escolher ler o texto base antes da fanfic; já o leitor que conhece o hipotexto, pode ser comparado a um jogador que já possui elementos que o ajudarão na construção da narrativa.

Por exemplo, na quinta tela que aparece, a autora emite um desejo em relação à jornada do leitor por meio da frase "E que a sorte esteja sempre ao [sic] seu favor!". Nesse momento, a autora não só indica a relação com o hipotexto, pois essa frase é usada recorrentemente na obra original, como também reforça a inserção do jogador na história. $\mathrm{O}$ pronome 'seu' é direcionado ao sujeito do outro lado da tela do computador, o qual agora se vê incluído no universo de Jogos Vorazes. Essa inclusão é reforçada nas primeiras linhas de Mockingjay ao utilizar na segunda sentença o nome escolhido nas primeiras telas (no caso deste artigo, o nome 'Magnólia'). É nesta página que a prática de leitura se modifica, pois nesse momento o jogador pode ser tanto co-autor quanto personagem da fanfic. Apesar de sutil, a interação possibilita que novos significados sejam criados pelo jogador, fato permitido pela programação da fanfic. Esses aspectos favorecem a experiência de leitura, visto que a escrita se torna colaborativa, ainda que de modo limitado.

Diferente de Mockingjay, a shortfic We remain é mais longa, direcionada a um público mais velho (14 anos) e expande a categoria de gêneros ao se apropriar da aventura e adicionar o drama e o romance ao hipotexto. Essa expansão permite que novas vozes façam parte da história. Além das vozes propostas pela autora @Laís, We remain também permite que o jogador contribua para a construção da narrativa por meio da interatividade.

De início, as duas produções se assemelham principalmente no que se refere ao contato feito com o jogador por meio da caixa de diálogos. Os cumprimentos ${ }^{11}$ demonstram a preocupação das autoras em estabelecer um diálogo com o leitor da fanfic. Em seguida, o agradecimento ${ }^{12}$ de @Laís pela leitura reforça a necessidade de estabelecer uma comunicação entre autora e jogador.

Ao solicitar que o jogador responda 'Qual seu nome?' (disponível na tela 3), a autora promove interlocução, por meio do uso do pronome 'seu', e demostra interesse pelo jogador ao solicitar o nome próprio desse sujeito, ou seja, individualiza a interação. Diferente de Mockingjay, não existem referências 
a novos personagens, logo, o referente proposto para o pronome 'seu' é o próprio jogador. Portanto, observa-se que há um esforço em We remain para que o jogador seja o protagonista da fanfic.

Em seguida, outra novidade, outra ponte com a realidade construída por meio das perguntas nas caixas de diálogo (Figura 3). Agora a autora quer desen- volver uma relação entre o protagonista e o par romântico. Para tanto, pergunta pelo nome da pessoa que o jogador gosta. Novamente, essa leitura é possibilitada pelo uso do pronome 'você' na caixa de diálogo, que assim como o possessivo 'seu' da tela anterior, estabelece a interlocução entre o usuário que lê e participa da fanfic com a autora.

Figura 3 - Tela 4

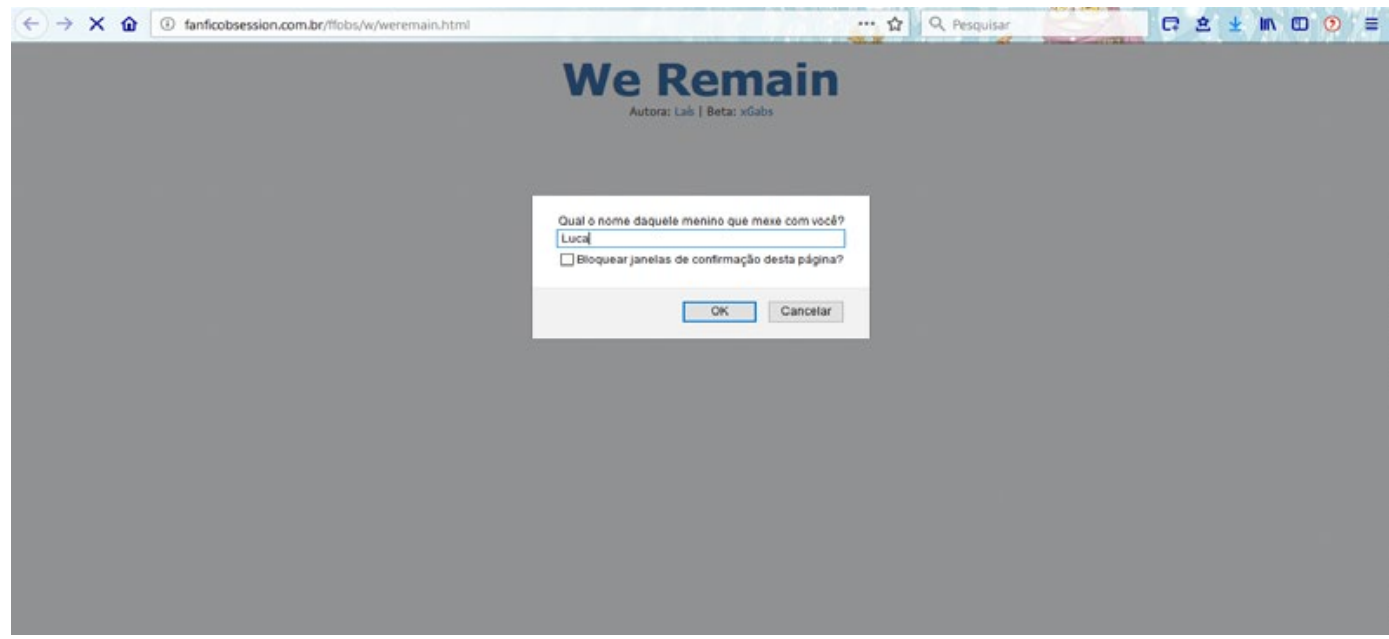

Fonte: as autoras (2018).

Nota: Qual o nome daquele menino que mexe com você? (Observação: o nome escolhido foi Luca).

De acordo com Rüdiger (2011), no que se refere ao jornalismo, as novas mídias permitiram o rompimento do monopólio exercido por empresas jornalísticas. Nessa perspectiva, é possível deslocar essa afirmação também para a produção de literatura ou entretenimento. Rüdiger (2011, p. 51), nesse sentido, afirma que:
As pessoas não apenas estão se tornando capazes de produzirem suas próprias informações, mas estão se redirecionando para essas novas fontes de conhecimento em que elas mesmas se transformam, com o desenvolvimento das novas tecnologias de comunicação.

Ao produzirem suas próprias histórias, nas quais, muitas vezes, é possível tomar 
parte por meio da interatividade proporcionada pelas programações dos websites, os usuários transformam-se. E essa transformação pode ser, grosso modo, o deslocamento do papel de consumidor de conteúdo para o de produtor. Além disso, a transformação pode ocorrer em um campo afetivo. Por exemplo, na sequência das telas (Tela 5), a autora pergunta ao jogador 'Qual a cor dos olhos dele?'. Nesse caso, a contração 'dele' agora possui um referente no mundo e é o mesmo utilizado para responder à questão anterior. $\mathrm{Na}$ sequência (Tela 6), novamente a fanfic estabelece uma relação entre a ficção e a realidade ao perguntar ao jogador ' $\mathrm{O}$ nome de um amigo dele'.

Essas informações ajudam a construir um panorama para a fanfic e, independente do nome escolhido para a personagem, seja do próprio jogador ou um nickname, em ambos os casos o jogador se torna não só leitor da fanfic, mas também co-autor. Isso porque os elementos da narrativa são por ele alterados, ou seja, a cada nova personagem, um novo significado para a história. No caso de uma fanfic derivada da literatura, como é o caso de We remain, ao mencionar (Tela 7) a expressão 'Bons Jogos Vorazes e que a sorte esteja sempre a seu favor!', a autora @Laís delimita o contexto no qual a história acontece. No entanto, a cada nova personagem inserida por meio da interatividade, encontra-se uma nova história.
Por fim, assim como em Mockingjay, depois de responder as perguntas feitas por meio das caixas de diálogo, a última tela refere-se à fanfic produzida. Em We remain, a diferença está no número de informações fornecidas pelo leitor: quatro. Além disso, a autora convida diretamente o leitor a fazer parte dessa história, construindo a narrativa de modo que a imersão seja personalizada.

Nesse aspecto, nota-se que o jogador, proposto por Cope e Kalantzis (2010), precisa conhecer as novas arquiteturas sociais e técnicas do ciberespaço (dimensão conhecida como 'conceitualização'). Sendo assim, a autora da fanfic, mesmo que não saiba codificar o texto para que a interação ocorra por meio das caixas de diálogos, conhece a beta-reader que tornará isso possível. Esses mecanismos permitem que o sujeito-leitor se insira em um contexto que só conhecia por meio dos livros e no qual talvez nunca tenha se imaginado.

Além disso, a autora @Laís propõe uma leitura multimodal para We remain. Um dos primeiros recursos observados refere-se ao uso da linguagem análoga à codificação HTML. Em um determinado momento na fanfic, o jogador se depara com o ponto de vista (Point of view ou, como utilizado nos websites de fanfics, o acrônimo POV) da personagem Luca, par romântico da personagem Magnólia. Tendo em vista que os recursos visuais e de programação ainda são bastante 
incipientes, o único modo de o leitor identificar a mudança de narrador na fanfic é por meio da expressão Luca POV's e POV's. Essa pontuação é bastante semelhante aos recursos utilizados em HTML para marcar o início e o fim de um item em negrito, por exemplo: “<b> Olá! </b>".

\section{Luca POV's}

Acertei o desgraçado que estava afogando, rapidamente a levantei da água. Ela tava apagada, entrei em desespero.

\section{$[\ldots]$}

- Eu consigo andar... - Começamos a caminhar. Estendi minha mão e se apoiou em mim, logo agarrando no meu braço para ter mais apoio.

POV's

Ademais, a autora elenca momentos para que sejam ouvidas músicas durante a leitura. Por meio de hiperlinks ${ }^{13}$, o jogador é direcionado para a música Demons da banda Imagine Dragons. Em outro momento, para a música Secrets da banda One Republic. Cada uma dessas músicas permite a criação de uma nova atmosfera para a história. De acordo com Cope e Kalantzis (2010), a multimodalidade permite que os significados sejam criados não só pelo texto escrito, mas nesse caso, pela música também. Pensando que os clipes são multimodais, pois relacionam imagem, melodia e texto verbal, é possível também depreender que cada um desses elementos pode interferir na produção de sentidos feita pelo jogador a respeito da fanfic.

\section{Algumas considerações}

Diante das questões discutidas neste artigo, é possível afirmar que as dimensões propostas por Cope e Kalantzis (2010) para compreender as novas mídias - $o$ agenciamento, a divergência, a multimodalidade e a conceitualização estão presentes de modo ainda sutil nas fanfics analisadas.

Entre essas sutilezas destaca-se quatro pontos. Primeiro, a mudança de postura do sujeito no ciberespaço, que deixa desloca-se de uma prática passiva de leitura para se tornar jogador ao atuar como co-autor das fanfics por meio da interatividade promovida pela programação em HTML ou, ainda, o autor-primeiro da fanfic, ao produzir, transformar, elaborar e modificar conteúdos (agenciamento). Segundo, a possibilidade de contrapor-se à ideia do autor de modo a propor uma nova leitura para o hipotexto e a possibilidade de reagir de diferentes modos (como comentários, botões de reação em mídias sociais, compartilhamento), aos conteúdos publicados (divergência). O terceiro ponto diz respeito à oportunidade de relacionar o texto verbal a textos espaciais, auditivos, gestuais, visuais de modo a oferecer diferentes formas de significação, por exemplo, o uso das músicas ao longo da shortfic (multimodalidade). E, por fim, a conceitualização, não tão perceptível na fanfic em si, mas que se apresenta nos 
menus dos websites, de modo a facilitar não só a compreensão das fanfics como também a localização delas.

Considerando a interatividade, é possível observar que a experiência do jogador por meio da escrita colaborativa é possibilitada pela programação em HTML e também pelos aspetos multimodais acionados. Nesse sentido, é possível analisar os diferentes meios pelos quais as colaborações dos jogadores são lidas para serem levadas às fanfics.

\section{Reading and writing in fanfic: moves from reader to player}

\section{Abstract}

Contemporaneity is marked by transformations related not only to the different sectors of society, but also to the way subjects interact in cyberculture and produce meaning. In this perspective, the practices of reading and writing have moved and gained new contours and possibilities. Considering this context, this article seeks to analyze some of the displacements of the reader made possible by the new media. Based on a qualitative-interpretative methodology and anchored in the ideas of the New London Group to discuss multilevels, analysis of the fanfic genre reveals that the dimensions proposed by multilevel theorists to understand new media agency, divergence, multimodality and conceptualization - are still subtly present in fanfics.

Keywords: Literacies. Multiliteracies. Cyberculture. Fanfic.

\section{Nota}

1 "To be a user of new media requires a kind of thinking which we will call 'conceptualization'. In the world of passive consumerism, you didn't need to know so much of what was inside the machine (mechanical, informational, sociocultural). To be a player today and not just a viewer / reader / consumer, you need to get your head around new social and technical architectures".

2 Tendo em vista a dimensão 'conceitualização', proposta por Cope e Kalantzis (2010), adota-se o termo 'jogador' para se referir ao sujeito que não apenas consome, mas que também produz conteúdo, visto que a perspectiva dos autores destaca o papel ativo dos sujeitos nas relações com as novas mídias.

3 A palavra fanfic é composta pelas palavras inglesas fan e fiction, fã e ficção, respectivamente; e caracteriza textos ficcionais produzidos por fãs.

4 Segundo Stam (2005), o hipotexto é o texto-base que dá origem ao hipertexto. Ao transpormos para o contexto das fanfics, é possível afirmar que essas produções são hipertextos.

5 Os fanclips são, grosso modo, clipes audiovisuais produzidos por fãs a partir de um hipotexto.

6 Grosso modo, músicas pop coreanas.

7 Disponível em: <http://www.fanficobsession. com.br/fanfics $/ \mathrm{m} /$ mockingjay.html $>$. Acesso em: 15 mai. 2018.

8 Disponível em: <http://fanficobsession.com.br/ ffobs/w/weremain.html>. Acesso em: 15 mai. 2018.

9 Tendo em vista que os autores de fanfics podem ser identificadas por meio de nomes de usuários ou pseudônimos, neste artigo, optou-se por utilizar a arroba (@) para identificar que o nome fornecido no website não é, necessariamente, o nome próprio do autor.

10 "É isso. Boa leitura! Não se esqueça de comentar $=\mathrm{D}$ ".

11 "Bem vinda à minha primeira fic!" (TELA 1).

12 "Obrigada por estar lendo!" (TELA 2).

13 Apenas o último link 'Clique aqui' encontra-se com problemas. Embora direcione o sujeito para a página do YouTube, o vídeo sequer aparece $\mathrm{e}$ seu nome não é disponibilizado. 


\section{Referências}

BAKHTIN, M. Problemas da poética de Dostoiévski. Trad. Paulo Bezerra. 5. ed. rev. Rio de Janeiro: Forense Universitária, 2010.

CAZDEN, Courtney; COPE, Bill; FAIRCLOUGH, Norman; GEE, Jim; et al. A pedagogy of Multiliteracies: designing social futures. Harvard Educational Review, Spring 1996. Disponível em: <http://newarcproject.pbworks. com/f/Pedagogy\%2Bof\%2BMultiliteracies_ New\%2BLondon\%2BGroup.pdf $>$. Acesso em: 16 maio 2018.

COPE, Bill. KALANTZIS, Mary. Multiliteracies: New Literacies, New Learning. Disponível em: <http://newlearningonline. com/files/2009/03/M-litsPaper13Apr08.pdf>. Acesso em: 16 maio 2018.

COPE, Bill; KALANTZIS, Mary. New media, new learning. In: COLE, David R.; PULEN, Darren L. (Ed.). Multiliteracies in motion: current theory and practice. New York: Routledge, 2010. p. 87-104.

KLEIMAN, Ângela. Os significados do letramento: uma nova perspectiva sobre a prática social da escrita. Mercado das Letras, 1995.

MARINHO, Marildes. O que é letramento? In: MARINHO, Marildes. CARVALHO, Gilcinei Teodoro. Cultura escrita e letramento. Belo Horizonte: Editora UFMG, 2010.

NEW LEARNING. Multiliteracies. 200-. Disponível em: <http://newlearningonline.com/ multiliteracies>. Acesso em: 16 maio 2018.

RÜDIGER, Francisco. A reflexão teórica em cibercultura e a atualidade da polêmica sobre a cultura de massas. Matrizes, a. 5, n. 1, jul./dez., 2011, São Paulo. p. 45-61. Disponível em: <http://meriva.pucrs.br/dspace/ bitstream/10923/9818/2/A_reflexao_teorica_em_cibercultura_e_a_atualidade_da_polemica_sobre_a_cultura_de_massas.pdf $>$. Acesso em: 16 maio 2018.
RÜDIGER, Francisco. As teorias da cibercultura: Perspectivas, questões e autores. Porto Alegre: Sulina, 2011. 